\title{
The mode I interlaminar fracture toughness of carbon fiber/epoxy resin composite with freezing after water absorption
}

\author{
H. Katogi \& K. Takemura \\ Department of Mechanical Engineering, Kanagawa University, Japan
}

\begin{abstract}
In this study, the effect of freezing after water absorption on the mode I interlaminar fracture toughness of carbon fiber reinforced plastics (CFRP) was investigated. Plain woven carbon fiber was used as reinforcement. Epoxy resin was used as the matrix. A water absorption test was conducted at $90^{\circ} \mathrm{C}$ for up to 500 hours. After water absorption, the specimens were kept at $-15^{\circ} \mathrm{C},-79^{\circ} \mathrm{C}$ and $-198^{\circ} \mathrm{C}$. The fracture surfaces of specimens were observed by using a scanning electronic microscope (SEM). Double cantilever beam tests were conducted at room temperature after water absorption and freezing. As a result, the following conclusions were obtained. CFRP can absorb a lot of water at an elevated temperature. At $90^{\circ} \mathrm{C}$, the rate of water absorption is about $1.5 \%$. The fracture toughness of water-absorbed CFRP is greater than that of virgin CFRP material in the case that the water absorbed ratio is more than $0.9 \%$. This is because the resin becomes ductile due to water absorption. In the case of freezing, at which the water absorption ratio is less than $0.9 \%$, the fracture toughness only almost increases. However, in the case of $1.5 \%$, the fracture toughness increases by about $50 \%$. This is also because of the interface between the fiber and the matrix. Keywords: carbon fiber, epoxy resin, mode I interlaminar fracture toughness, water absorption, freezing, SEM.
\end{abstract}

\section{Introduction}

Carbon fiber reinforced plastics (CFRP) have high specific strength and stiffness and are used as the structural materials of airplanes. Generally, the weight fraction of CFRP in the structural materials of an airplane is 50\% [1]. However, CFRP also has a demerit, which is anisotropy. Also, the interlaminar shear 
strength and interlaminar fracture toughness of CFRP are not enough. So, delaminations in CFRP occur easily when a crash/accident occurs.

Airplanes usually fly at low temperatures in a moisture environment of rainy skies. Many papers about CFRP, studied under varying temperatures and moisture environments, have been published [2-7]. When CFRP absorbs water, the degradation of the fiber/resin interface [8] and the ductilization of epoxy resin as the matrix [9] occurs. So, the interfacial adhesion between the fiber and the resin greatly affects the decrease in interlaminar fracture toughness of CFRP. Furthermore, there was a report, which stated that the interlaminar fracture toughness of CFRP, from $-100^{\circ} \mathrm{C}$ to $200^{\circ} \mathrm{C}$, was dependent on the environmental temperature [10].

Some papers have been published about the effects of water absorption and the temperature on the interlaminar fracture toughness of CFRP. But, the interlaminar fracture toughness of CFRP in a combined environment of water absorption and temperature is not discussed. In this study, the mode I interlaminar fracture toughness of CFRP, with freezing after water absorption, was investigated.

\section{Specimen}

Plain woven carbon fiber (Torayca cloth CO6343, Toray Co., Ltd.) was used as reinforcement. Epoxy resin (jER 828, Mitsubishi Chemical Co., Ltd.) was used as the matrix. The hand lay-up method is used for molding using a hot press machine. Twelve layers of CFRP were sued. Teflon film was used as the initial crack at the middle layer. The thickness of the teflon file is $30 \mu \mathrm{m}$. The initial crack length was $34 \mathrm{~mm}$. The molding pressure was $2 \mathrm{MPa}$, the molding temperature was $90^{\circ} \mathrm{C}$ and the molding time was 3 hours. The fiber volume fractions of CFRP were $64 \%$. The specimen size was $150 \mathrm{~mm}$ in length, $20 \mathrm{~mm}$ wide and $3 \mathrm{~mm}$ thick.

\section{Test method}

\subsection{Water absorption test method}

The water absorption test was conducted in distilled water at $90^{\circ} \mathrm{C}$. The immersion times were 24 hours, 100 hours and 500 hours. In the water absorption test, the mass of specimens are measured. The water absorption rate of CFRP was calculated by the following equation (1).

$$
c=\frac{m_{1}-m_{0}}{m_{0}} \times 100
$$

where, $C$ is water absorption rate, $m_{0}$ is mass before water absorption and $m_{1}$ is the mass after water absorption. 


\subsection{Freezing after water absorption test method}

After the water absorption test, the freezing process is conducted. In this case, the freezing temperatures were set at $-15^{\circ} \mathrm{C}$ and $-79^{\circ} \mathrm{C}$, the specimens were kept for 24 hours. At $-196^{\circ} \mathrm{C}$, the specimens were kept for $10 \mathrm{~min}$. Specimens after freezing were kept at room temperature for 24 hours. This is known as the process of thawing.

In this study, the untreated specimen, the frozen specimen at $-15^{\circ} \mathrm{C},-79^{\circ} \mathrm{C}$ and $-198^{\circ} \mathrm{C}$ are named virgin, virgin $\left(-15^{\circ} \mathrm{C}\right)$, virgin $\left(-79^{\circ} \mathrm{C}\right)$ and virgin $\left(-198^{\circ} \mathrm{C}\right)$, respectively. The water absorbed specimen and the frozen specimen at $-15^{\circ} \mathrm{C}$, $-79^{\circ} \mathrm{C}$ and $-198^{\circ} \mathrm{C}$ after water absorption are named wet, frozen $\left(-15^{\circ} \mathrm{C}\right)$, frozen $\left(-79^{\circ} \mathrm{C}\right)$ and frozen $\left(-198^{\circ} \mathrm{C}\right)$ respectively.

\subsection{Double cantilever beam (DCB) test method}

The DCB test was conducted based on the Japanese Industrial Standard (JIS) K 7086. Figure 1 shows a schematic drawing of the specimen for the DCB test. The initial crosshead speed was $0.5 \mathrm{~mm} / \mathrm{min}$. After the initial crack, the crosshead speed was changed to $1.0 \mathrm{~mm} / \mathrm{min}$. The number of specimens was five. The environmental temperature was room temperature. $C O D$ is the crack opening displacement and $a$ is the crack growth.

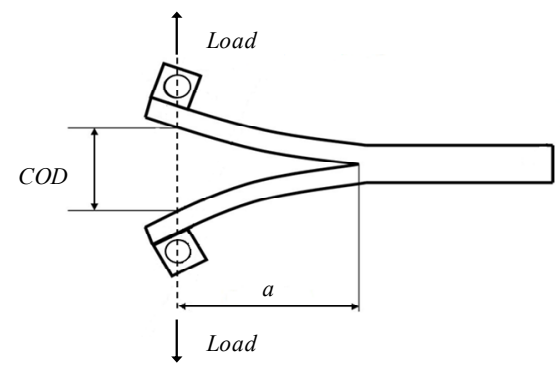

Figure 1: Schematic drawing of specimen for DCB test.

\subsection{Scanning Electron Microscope (SEM) observation}

After the mode I fracture toughness test, the fracture surfaces of CFRP were observed by using an SEM (S-4000, Hitachi high-tech technologies Co., Ltd.).

\section{Results and discussion}

\subsection{Water absorption test}

Figure 2 shows the water absorption rate in a $90^{\circ} \mathrm{C}$ environment. CFRP can absorb a lot of water at an elevated-temperature environment. The water absorption rate of CFRP increased with an increase of water absorption time. At $90^{\circ} \mathrm{C}$, the rate of water absorption is about $1.5 \%$. 


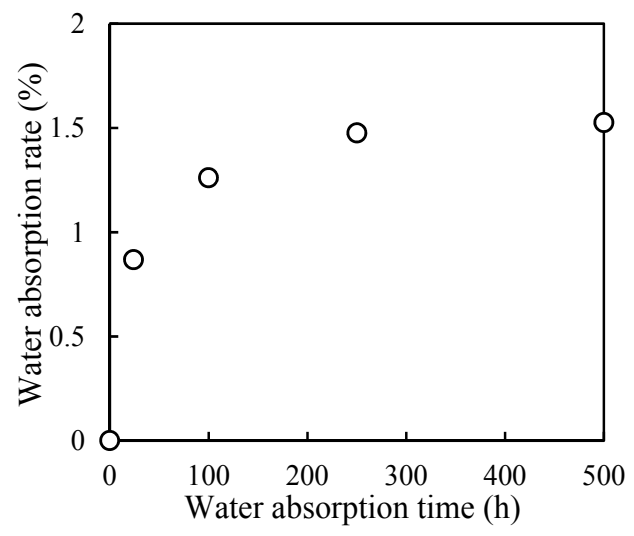

Figure 2: Water absorption rate at $90^{\circ} \mathrm{C}$ environment.

\subsection{The DCB test}

Figure 3 shows the mode I interlaminar fracture toughness of Virgin and Wet specimens. The initial mode I interlaminar fracture toughness of virgin increased with an increase of the water absorption rate. The mode I interlaminar fracture toughness of Virgin and Wet $(24 \mathrm{~h}, 0.9 \%)$ almost did not change within the crack growth process. The mode I interlaminar fracture toughness of Wet $(100 \mathrm{~h}$, $1.2 \%)$ and Wet $(500 \mathrm{~h}, 1.5 \%)$ at the crack growth process were higher than that of Virgin. Furthermore, the scattering of the mode I interlaminar fracture toughness of Wet $(100 \mathrm{~h}, 1.2 \%)$ and Wet $(500 \mathrm{~h}, 1.5 \%)$ at the crack growth process were relatively large. The epoxy resin as the matrix became ductilization when CFRP absorbed water [9]. This behavior can be directly related with the interfacial adhesion. Therefore, the mode I interlaminar fracture toughness of CFRP increased as the interfacial adhesion was improved.

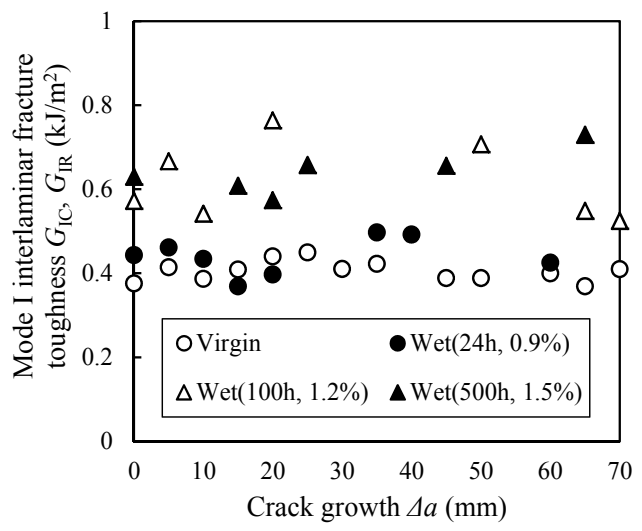

Figure 3: Mode I interlaminar fracture toughness of water absorbed CFRP. 
Figure 4 shows the mode I interlaminar fracture toughness of Virgin and Frozen. The mode I interlaminar fracture toughness of Virgin decreased with a decrease of temperature (except at $-15^{\circ} \mathrm{C}$ ). The scattering of the mode I interlaminar fracture toughness of Frozen Virgin at the crack growth process was large. Therefore, the mode I interlaminar fracture toughness of frozen CFRP decreased by the brittleness of epoxy resin as the matrix [11]. In the case of the water absorption rate at $0.9 \%(24 \mathrm{~h})$, the mode I interlaminar fracture toughness of Frozen almost did not change. But the scattering of the mode I interlaminar fracture toughness of Frozen at crack growth process was large, similar to Wet. Thus, the frozen temperature was not effective in the improvement of the mode I interlaminar fracture toughness of $0.9 \%$ water absorbed CFRP. In the case of the water absorption rate at $1.5 \%(500 \mathrm{~h})$, the mode I interlaminar fracture toughness of Frozen was higher than that of Virgin. The mode I interlaminar fracture toughness of frozen $\left(-79^{\circ} \mathrm{C}\right)$ was lower than that of frozen $\left(-15^{\circ} \mathrm{C}\right)$. But the fracture toughness of frozen $\left(-198^{\circ} \mathrm{C}\right)$ was also high. In the case of freezing, whose water absorption ratio is less than $0.9 \%$, the fracture toughness almost increases. But in the case of $1.5 \%$, the fracture toughness increases by about $50 \%$. This is also because of the interface between the fiber and the matrix.

\subsection{SEM observation}

Figure 5 shows the fracture surface of CFRP after the DCB test. Debonding in the fracture surface of Virgin was not found. But, the debonding between the fiber and the matrix was found on fracture surface of wet and frozen specimens. In the case of the water absorption rate at $1.5 \%$, the fracture toughness increased. So, the crack may occur in the case that fracture toughness is big.

\section{Conclusions}

In this study, the mode I interlaminar fracture toughness of carbon fiber/epoxy resin composite with freezing after water absorption was investigated.

The following conclusions are obtained:

(1) CFRP can absorb a lot of water at the elevated temperature environment. At $90^{\circ} \mathrm{C}$, the rate of water absorption is approximately $1.5 \%$.

(2) The fracture toughness of water-absorbed CFRP is greater than that of virgin CFRP material in the case that the water absorbed ratio is more than $0.9 \%$. This is because the resin becomes ductile due to water absorption.

(3) In the case of freezing, in which the water absorption ratio is less than $0.9 \%$, the fracture toughness almost increases. But in the case of the ratio being $1.5 \%$, the fracture toughness increases to about $50 \%$. This is also because of the interface between the fiber and the matrix. 


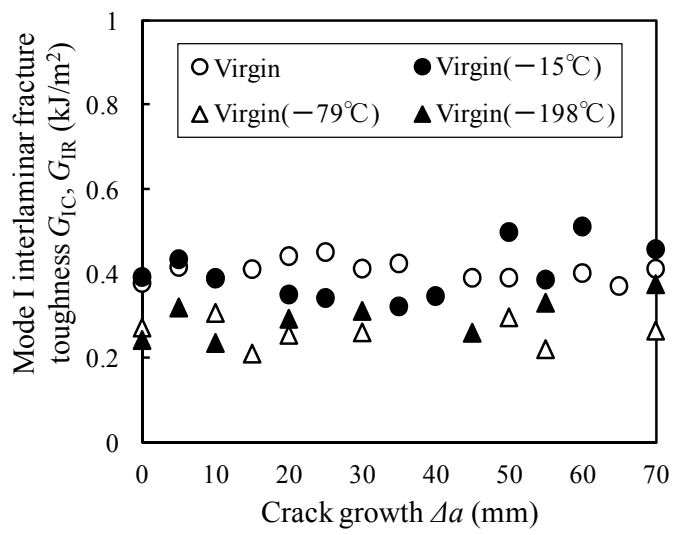

(a)

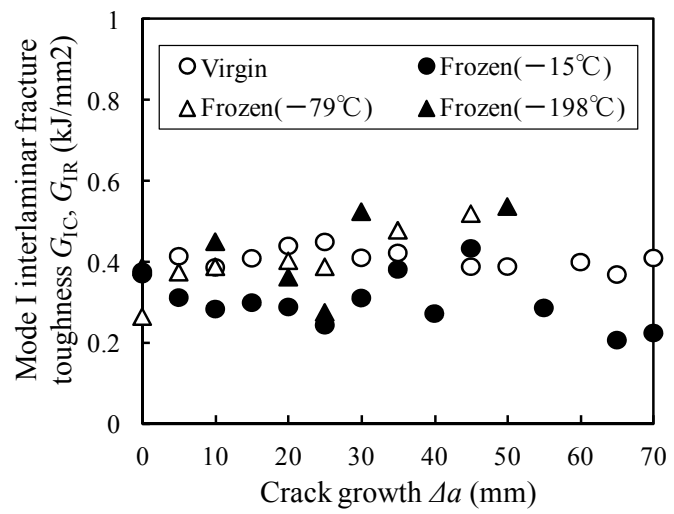

(b)

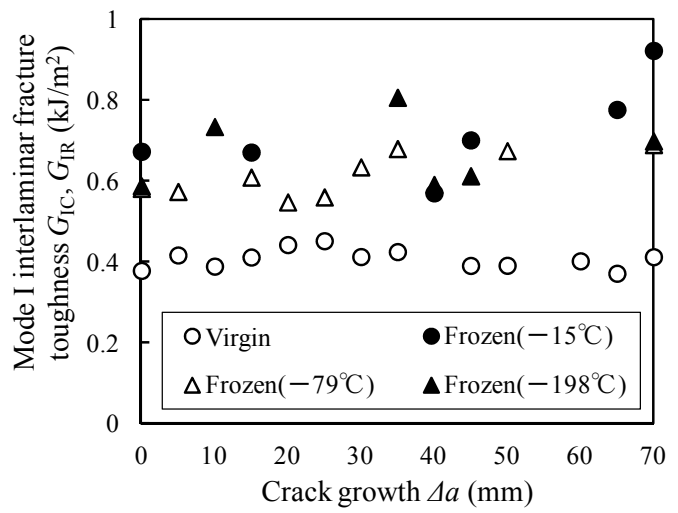

(c)

Figure 4: Mode I interlaminar fracture toughness of frozen. (a) Virgin, (b) Frozen (24 h, 0.9\%), (c) Frozen (500 h, 1.5\%). 


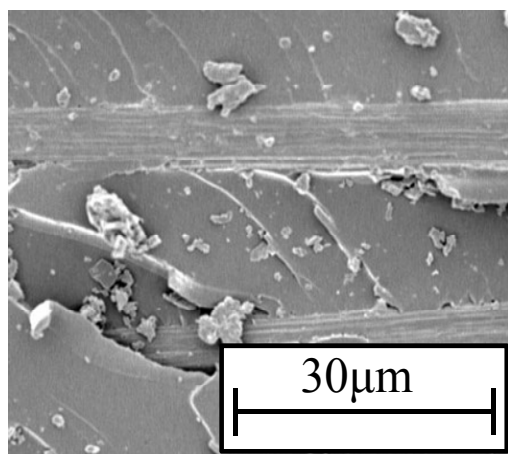

(a)

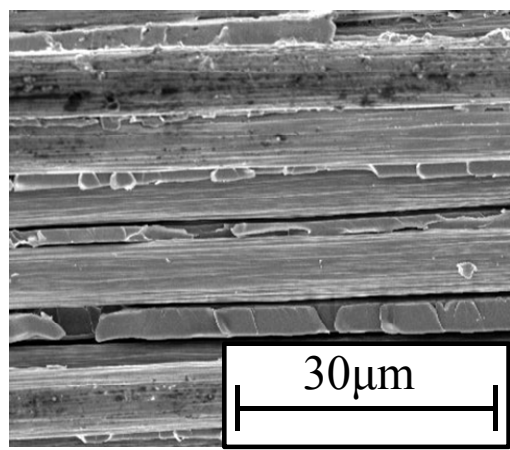

(c)

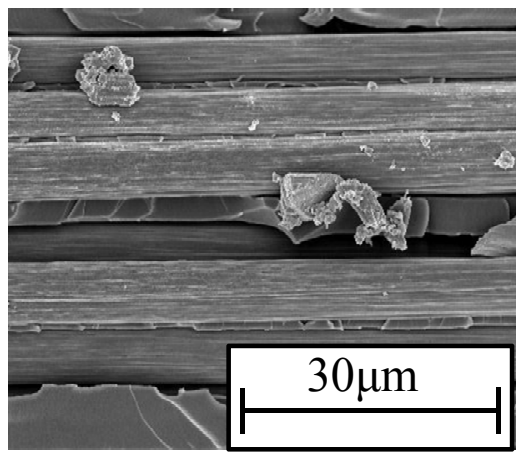

(b)

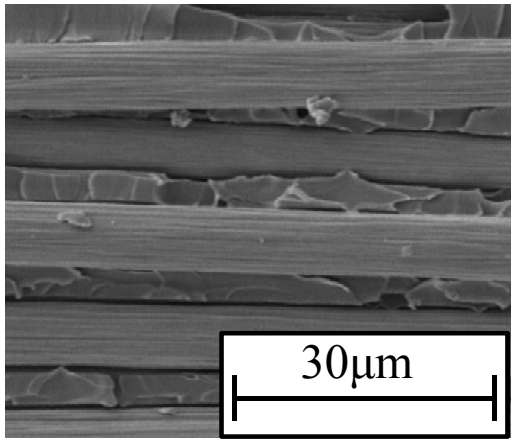

(d)

Figure 5: Fracture surface of CFRP after DCB test (Wet $(500 \mathrm{~h}, 1.5 \%)$ ). (a) Virgin, (b) We, (c) Frozen $\left(-79^{\circ} \mathrm{C}\right)$, (d) Frozen $\left(-198^{\circ} \mathrm{C}\right)$.

\section{References}

[1] Boeing, Aircraft and Composite recycling, Environmental Technotes, 12, pp. 1-4, 2007.

[2] Katogi, H., Takemura, K. \& Shimamura Y., Mechanical properties of Carbon Fiber Reinforced Plastics under Hot-Wet Environment, Key Engineering Materials, 462-463, pp. 207-212, 2011.

[3] Kim, H. J. \& Takemura, K., Influence of Water Absorption on Creep Behavior of Carbon Fiber/Epoxy laminates, Proceedia Engineering, 10, pp. 2731-2736, 2011.

[4] Kalfon, E., Harel, H., Marom, G., Drukker, E., Green, K. A. \& Kressel, I., Delamination of Laminated Composites Under the Combined Effect of Nonuniform Heating and Absorbed Moisture, Polymer Composites, 26, pp. 770-777, 2005. 
[5] Fujieda, H., Sekine, S., Nakada, M., Miyano, Y., Kuraishi, A. \& S.W., Tsai, Applicability of Time-Temperature-Water Absorption Superposition Principle for Flexural of CFRP Laminates, JSME International Journal Series A, 46, pp. 467-472, 2003.

[6] Wan, Y., Z., Han, K., Y., Wang, Y., L. \& Huang, Y., Moisture Sorption of Three-Dimensional Vraided Carbon Fiber-Epoxy Composite under Different Media, Journal of Applied Polymer Science, 97, pp. 507-512, 2005.

[7] Silva, M.R.R.L., D’Almeida, J.R.M. \& Calado, V., Variation of the Thermal Diffusivity of Glass and Carbon Fiber-Epoxy Composites as a Function of Water Absorption, Polymer Testing, 28, pp. 543-547, 2009.

[8] Aoki, Y., Yamada, K., Ishikawa, T. \& Ben, G., Effect of Water Absorption and Thermal Environment on Compression after Impact (CAI) Characteristics of CFRP Laminates, Journal of the Japan Society for Composite Materials, 32, pp. 163-170, 2006 (in Japanese).

[9] Matsuda, S., Hoji, M. \& Ochiai, S., Effect of Water Environment on Mode II Delamination Fatigue in Interlayer-Toughened CFRP, JSME International Journal Series A, 42, pp. 421-428, 1999.

[10] Shimizu, M., Adachi, T., Araki, M., Nakahara, T. \& Matsumoto, H., Influence of Thermal Environment on Mode I and Mode II Interlaminar Fracture Toughness in Unidirectional CFRP Laminates, Transaction of the Japan Society of Mechanical Engineers A, 65, pp. 282-285, 1999 (in Japanese).

[11] Yang, G., Fu, S., Y. \& Yang, J., P., Preparation and Mechanical Properties of Modified Epoxy Resins with Flexible Diamines, Polymer, 48, pp. 302-310, 2007. 